\title{
BMJ
}

\section{Meeting information needs of patients with incurable progressive disease and their families in South Africa and Uganda: multicentre qualitative study}

\author{
Lucy Selman, research associate, ${ }^{1}$ Irene J Higginson, professor, ${ }^{1}$ Godfrey Agupio, research nurse, ${ }^{2}$ \\ Natalya Dinat, director, ${ }^{3}$ Julia Downing, deputy executive director, ${ }^{4}$ Liz Gwyther, senior lecturer, ${ }^{5}$ \\ Thandi Mashao, research nurse, ${ }^{6}$ Keletso Mmoledi, palliative care service team leader, ${ }^{3}$ Anthony P Moll, chief \\ medical officer, ${ }^{7}$ Lydia Mpanga Sebuyira, head of training department, ${ }^{8}$ Barbara Panajatovic, chief executive, ${ }^{9}$ \\ Richard Harding, senior lecturer ${ }^{1}$
}

${ }^{1}$ King's College London,

Department of Palliative Care,

Policy and Rehabilitation, King's

College London, London SE5 9RJ

${ }^{2}$ Hospice Africa Uganda,

PO Box 7757, Kampala, Uganda

${ }^{3}$ Witwatersrand Palliative Care, PO Box 212, Pimville, Soweto 1808, Johannesburg, Gauteng,

South Africa

${ }^{4}$ African Palliative Care

Association, PO Box 72518,

Kampala

${ }^{5}$ Hospice Palliative Care

Association of South Africa,

PO Box 38785, Pinelands 7430,

Cape Town, Western Cape, South

Africa

${ }^{6}$ Palliative Medicine Unit,

University of Cape Town

Observatory 7925, Cape Town

${ }^{7}$ Church of Scotland Hospital, P/ Bag X502, Tugela Ferry 3010,

KwaZulu Natal, South Africa

${ }^{8}$ Infectious Diseases Institute, Faculty of Medicine, Makerere University, PO Box 22418, Kampala

${ }^{9}$ Msunduzi Hospice,

PO Box 220223, Pietermaritzburg 3208, KwaZulu Natal

Corresponding author: L Selman lucy.selman@kcl.ac.uk

Cite this as: $B M J$ 2009;338:b1326 doi:10.1136/bmj.b1326

\section{ABSTRACT}

Objectives To explore the information needs of patients with progressive, life limiting disease and their family caregivers in South Africa and Uganda and to inform clinical practice and policy in this emerging field. Design Semistructured qualitative interview study. Setting Four palliative care services in South Africa and one in Uganda, covering rural, urban, and peri-urban locations.

Participants 90 patients and 38 family caregivers enrolled in palliative care services; 28 patients had cancer, 61 had HIV infection (including 6 dual HIV/cancer diagnoses), and 1 had motor neurone disease.

Results Five themes emerged from the data. (1) Information sources: a lack of information from general healthcare providers meant that patients and caregivers had to draw on alternative sources of information. (2) Information needs: patients and caregivers reported needing more information in the key areas of the causes and progression of the disease, its symptoms and treatment, and financial/social support. (3) Impact of unmet needs: poor provision of information had a detrimental effect on patients' and caregivers' ability to cope. (4) Communication: negative experiences of communication with general healthcare staff were reported (misinformation, secrecy, insensitivity). (5) Barriers to effective provision of information: barriers related to symptoms, culture, time constraints in hospital, and paternalism in general health care.

Conclusions Lack of information was a major theme for both patients and carers, who had important unanswered questions relating to living with a progressive incurable disease. Evidence based recommendations for clinicians are presented, including the proactive provision of information tailored to individual patients and families.

\section{INTRODUCTION}

In 200722.5 million people with HIV infection lived in sub-Saharan Africa, 1.7 million adults and children became infected with HIV, and 1.6 million people died of AIDS. ${ }^{1}$ Provision of antiretroviral therapy has expanded dramatically in the region, but the scale of need means that only $23 \%$ of the estimated 4.6 million people in need of such treatment in this region are receiving it. ${ }^{2}$ Access to antiretroviral therapy is crucial to prolong life, but patients on antiretroviral therapy also need palliative care..$^{3-6}$ These needs relate to side effects of treatment, underlying infection, and the impact of living with the diagnosis. ${ }^{\text {? }}$

In addition to the rising burden of HIV, cancer and other non-communicable diseases are becoming urgent public health concerns in Africa. In a recent review, Parkin et al report that approximately one in five deaths in sub-Saharan Africa are due to cancer; in women, the lifetime risk of dying from cancer in Africa is almost double the risk in developed countries. ${ }^{8}$ The number of people in Africa aged over 60 is projected to quadruple by 2050 . As the population ages, the lifetime risk of cancer is expected to increase by $50-60 \%$ and the annual number of cases to rise from 650000 to 2.2 million. ${ }^{8}$

Palliative care is therefore an essential component of public health services in sub-Saharan Africa, but current provision in the region is patchy and coverage is poor. ${ }^{69}$ Successful models of community based and home based palliative care in the region have been described, but so have considerable challenges, ${ }^{6}$ including lack of access to essential drugs, poor social conditions, criminality and urban violence, high morbidity and mortality in health workers, and a lack of trained professionals. ${ }^{10-13}$

Despite the difficulties of this context, Uganda and South Africa are internationally recognised to have made sustained and important gains in the provision of palliative care, largely through community based hospices and home based palliative care services. Uganda is the only country in Africa to have made palliative care for people with HIV and cancer a priority in its national health plan (2001-5). ${ }^{14}$ Oral morphine is freely available in districts with specialist palliative 
care clinicians, and nurse prescribing is legislated, ${ }^{15}$ although problems with roll-out of morphine have been documented. ${ }^{16}$ In South Africa, progress has involved the inclusion of morphine as an essential drug in primary care, with national standards for management of cancer pain. ${ }^{17} 18$ The first palliative care services were hospices founded in the 1980 s along UK lines $;{ }^{17}$ however, palliative care is now provided through hospitals and home care providers across the country. South Coast Hospice (one of our participating facilities) has pioneered the successful integrated community based home care model, and a national network of hospices operates according to accredited standards.

Meeting the information needs of patients with progressive, life limiting conditions and their families, in a timely and appropriate way, is a key concern of palliative care. A large body of evidence from resource rich countries shows that lack of information on the causes, symptoms, treatment, and progression of disease adversely affects patients' and caregivers' abilities to cope with and manage serious illness and that good communication improves outcomes. ${ }^{19-22}$ However, to date very little research has been done in this area in

\section{Box 1 Schedules for semi-structured interviews with patients and caregivers}

\section{Interview schedule-patients \\ - Please tell me about when you first became ill \\ - What problems have you had due to your illness? Prompts: \\ Physical pain and symptoms \\ Emotional/worry/psychological/spiritual \\ Economic/social \\ - Do you have any family around you? Do any of them look after you? \\ - Are there any other people whom you look after? \\ - Do you think your family have had any worries? If yes, what are they? \\ - Where have you got your information from about your illness? Has it been enough? What would you like more information about, if anything? \\ - Have you been able to find peace during your illness? If yes, how? \\ - Do you have a religion or God that you believe in? If yes, has anyone helped you in thinking about your God or your religion? \\ - Do you feel that you need to make any plans for your future or for your family? If yes, what plans?}

Interview schedule-family caregivers

- Please tell me about when the patient first became ill

- What problems have you had due to their illness? Prompts:

Emotional/worry/psychological/spiritual

Economic/social

Family problems-for example, care of children

- Are there any other people whom you look after?

- Does anyone care for you and give you support? If yes, who?

- Do you think your family have had any worries? If yes, what are they?

- Where have you got your information from about the illness? Has it been enough? What would you like more information about, if anything?

- Do you feel that you need to make any plans for the future for you or your family? If yes, what plans?
Africa, ${ }^{623}$ and the extent to which findings from the developed world are applicable in the African context is not clear. Illiteracy, poverty, and multiple deaths from AIDS within the same family are common in sub-Saharan Africa and likely to affect patients' and caregivers' needs. ${ }^{2425}$

Although few studies have looked at specific palliative care needs in Africa, some exceptions exist. For example, Murray et al did a qualitative study of 24 patients with incurable cancer and their caregivers in Kenya and identified needs including pain control and help with finances. ${ }^{2627}$ Similarly, in a Ugandan survey of 173 terminally ill patients, Kikule et al identified needs for pain and symptom control, counselling, and financial support. ${ }^{28}$ However, little has been done to understand patients' and caregivers' needs for information. Consequently, evidence is lacking on how best to meet such needs at a health service level. Access to reliable information and advice through such services is essential for patients and families living with incurable progressive disease to make informed decisions and plan for the future.

This qualitative study aimed to explore the information needs of patients and caregivers attending palliative care services in South Africa and Uganda, identify the areas in which patients and caregivers consider that they need more information, and understand their past experiences of communicating with healthcare staff. By generating the first body of evidence on this key component of palliative care in Africa, we aimed to inform service development and clinical practice.

\section{METHODS}

Design and setting

The study reported here is the qualitative component of a large, 30 month collaborative study (the Encompass project). The qualitative method used data from semistructured qualitative interviews with patients and caregivers enrolled at four non-profit palliative care services in South Africa and one in Uganda. Qualitative methods are most appropriate in exploratory, indepth research of this nature. ${ }^{29}$ We selected the participating sites as established palliative care services able to support research and fulfil recruitment criteria for the study and representing a diverse range of service types (home based care and inpatient units). Table 1 shows further details on the services.

\section{Recruitment and sampling}

Recruitment took place at the five participating palliative care sites. A trained palliative care research nurse was based at each site (GA, TM, KM, and two others). At each service, either clinical staff or the study research nurse approached eligible patients and caregivers, either on home visits or in the ward. Site A also recruited existing patients by telephone.

We generated a purposive sample of patients and caregivers over a period of 10 weeks to a maximum target of 20 patients and 10 caregivers at each site. On the basis of the researchers' previous experience and the literature ${ }^{3031}$ we estimated that recruitment 


\begin{tabular}{|c|c|c|c|c|c|c|c|c|}
\hline Site & Area served & Service type & Source of most of funding & $\begin{array}{l}\text { No of patients } \\
\text { cared for } \\
(2007-8)\end{array}$ & Type of patients cared for & $\begin{array}{l}\text { Patients } \\
\text { recruited } \\
(n=90)\end{array}$ & $\begin{array}{l}\text { Family } \\
\text { carers } \\
\text { recruited } \\
(n=38)\end{array}$ & $\begin{array}{c}\text { Total } \\
(n=128)\end{array}$ \\
\hline A & Urban & $\begin{array}{l}\text { Homecare, day care, outpatient } \\
\text { clinic, hospital consultancy, and } \\
\text { outreach to healthcare clinics } \\
\text { through three branches }\end{array}$ & $\begin{array}{l}\text { Local, national, and } \\
\text { international donors }\end{array}$ & 2396 & $\begin{array}{l}\text { Patients with advanced cancer } \\
\text { or advanced HIV }\end{array}$ & 20 & 10 & 30 \\
\hline $\mathrm{B}$ & $\begin{array}{l}\text { Urban } \\
\text { township }\end{array}$ & $\begin{array}{l}\text { Four sister hospices, all offering } \\
\text { short term ( } 2-3 \text { week) inpatient } \\
\text { care; two also offer home care }\end{array}$ & $\begin{array}{l}\text { Local, national, international } \\
\text { donors }\end{array}$ & 1607 & $\begin{array}{l}\text { Patients with HIV, cancer, or } \\
\text { other progressive incurable } \\
\text { conditions }\end{array}$ & 20 & 3 & 23 \\
\hline $\mathrm{C}$ & $\begin{array}{l}\text { Urban } \\
\text { township }\end{array}$ & $\begin{array}{l}\text { Homecare, outpatient clinic, } \\
\text { and inpatient unit attached to } \\
\text { hospital }\end{array}$ & $\begin{array}{l}\text { Government and international } \\
\text { donors }\end{array}$ & 1818 & $\begin{array}{l}\text { Patients with cancer, HIV, or } \\
\text { MND, from diagnosis until point } \\
\text { of death }\end{array}$ & 12 & 3 & 15 \\
\hline $\mathrm{D}$ & Rural & $\begin{array}{l}\text { Homecare and inpatient unit } \\
\text { close to hospital }\end{array}$ & $\begin{array}{l}\text { Global Fund for AIDS, } \\
\text { Tuberculosis and Malaria }\end{array}$ & 847 & $\begin{array}{l}\text { Patients with HIV, from } \\
\text { diagnosis until point of death }\end{array}$ & 18 & 12 & 30 \\
\hline $\mathrm{E}$ & $\begin{array}{l}\text { Rural, peri- } \\
\text { urban, and } \\
\text { urban } \\
\text { township }\end{array}$ & $\begin{array}{l}\text { Homecare, day care, and } \\
\text { inpatient unit }\end{array}$ & $\begin{array}{l}\text { Local, national, and } \\
\text { international donors, including } \\
\text { Global Fund for AIDS, } \\
\text { Tuberculosis and Malaria }\end{array}$ & 1290 & $\begin{array}{l}\text { Patients with cancer, HIV, or } \\
\text { MND, from diagnosis until point } \\
\text { of death }\end{array}$ & 20 & 10 & 30 \\
\hline
\end{tabular}

$\mathrm{MND}=$ motor neurone disease.

of 15-20 patients at each site would achieve data saturation when data from each site were analysed separately. We set a target of seven to 10 caregivers per site because of time constraints and the anticipated difficulty of accessing caregivers at some home based care services. This gave a target sample of 75-100 patients and 35-50 caregivers overall.

We included participants if they were adult (at least 18 years old) patients or family caregivers, able to give informed consent, judged to be physically and mentally well enough to participate by their clinical staff, and able to speak either English or one of six local languages fluently (isiXhosa, isiZulu (Gauteng and KwaZulu Natal dialects), SeSotho, SeTswana, Luganda, and Runyoro). The purposive sampling frame took account of place of care (community/inpatient/outpatient), age, sex, location, and ethnic group, in order to reflect the diversity of possible experiences.

Information sheets were translated from English (see data collection) into appropriate local languages. Participants gave written informed consent before the interview; illiterate participants had the information sheet and consent form read to them and marked rather than signed their consent. ${ }^{3233}$

\section{Data collection}

We drafted semistructured topic guides for face to face interviews with patients and caregivers (box 1). The participating sites translated topic guides, information sheets, and consent forms from English into local languages (isiXhosa, isiZulu (Gauteng and KwaZulu Natal dialects), SeSotho, SeTswana, Luganda and Runyoro); staff fluent in both English and the relevant local language crosschecked them. The University of KwaZulu Natal did the KwaZulu Natal isiZulu translation and the University of Cape Town did the isiXhosa translation.

The research nurse based at each site did the interviews, either in the participant's home or at the site during a routine outpatient visit or inpatient admission.
At site A, two trained local interviewers assisted the research nurse, owing to the long distances between the catchment areas of the service's satellite clinics. At site $\mathrm{E}$, one trained local interviewer assisted, as the research nurse did not speak isiZulu. Interviews took place in the language chosen by the participant and lasted 20-60 minutes.

We also collected demographic data for both patients and caregivers. In line with international guidelines, we defined a diagnosis of AIDS as the presence of a CD4 cell count below 200 cells/ $\mu$ l or an AIDS defining illness such as extrapulmonary tuberculosis. We used the Eastern Cooperative Oncology Group (ECOG) performance status to measure patients' functional status. ${ }^{34}$

\section{Analysis}

The research nurses tape recorded the interviews, transcribed them verbatim, and translated them into English. They discussed the translation of complex terms or phrases with service staff members and the principal investigators at each site, who also peer reviewed the transcripts to check the accuracy of translations. Transcripts were imported into NVivo v7 for content analysis of themes. ${ }^{35}$

LS coded each transcript line by line, creating a coding frame of themes generated directly from the data and organised according to specific research questions. Through a constant comparison approach to analysis, sub-themes were generated and deviant cases highlighted within each theme, in order to describe the breadth of the data. ${ }^{36}$ To increase the validity of findings, a second researcher $(\mathrm{RH})$ reviewed a random sample of five transcripts from each service to ensure the internal consistency and independence of themes and to ascertain inter-rater coding reliability. ${ }^{35}$ Interrater coding reliability was high; LS identified only minor inconsistencies in coding and resolved them iteratively by reference to the coding frame and in discussion with RH. ${ }^{37}$ To ensure open discussion of data 
collection and analysis throughout the project, the project team had monthly conference calls and attended three face to face meetings a year in South Africa. At the project meetings, held at key points during the analysis process, we presented preliminary findings to the local project team for discussion. We later incorporated feedback into data analysis to improve the validity of the findings. We analysed demographic data by using frequencies in SPSS v15 and imported them into NVivo v7.

\section{RESULTS}

Sample characteristics

We recruited 128 participants across the five sites $(90$ patients, 38 caregivers) (table 1). Interviews took place in isiZulu (n=55), English (34), isiXhosa (13), Luganda (13), Runyoro (6), SeSotho (6), and SeTswana (1). All interviewers and participants were fluent in the language in which the interview was done.

\begin{tabular}{|c|c|c|}
\hline Demographic characteristic & Patients $(n=90)$ & Carers $(n=38)$ \\
\hline Mean (SD; range) age (years) & $43.2(15.4 ; 18-84)$ & $44.8(17.5 ; 19-77)^{\star}$ \\
\hline Female & $58(64)$ & $32(84)^{\star}$ \\
\hline \multicolumn{3}{|l|}{ Responsible for children? } \\
\hline Yes & $68(76)$ & $30(79)^{\star}$ \\
\hline Mean (SD; range) No of children & $2.8(1.8 ; 1-9)$ & $3.1(1.6 ; 1-8)$ \\
\hline Mean (SD; range) household size & $5.2(5.0 ; 1-20) \dagger$ & $7.1(3.5 ; 2-20)^{\star}$ \\
\hline \multicolumn{3}{|l|}{ Location of home: } \\
\hline Urban & $23(26)$ & $4(11)$ \\
\hline Peri-urban & $26(29)$ & $10(26)$ \\
\hline Rural & $41(46)$ & $24(63)$ \\
\hline \multicolumn{3}{|l|}{ Primary diagnosis: } \\
\hline Motor neurone disease & $1(1)$ & \multirow{3}{*}{ NA } \\
\hline Cancer only & $28(31)$ & \\
\hline HIV & $61(68)$ & \\
\hline \multicolumn{3}{|l|}{ Of HIV positive patients: } \\
\hline On antiretroviral therapy & $39(64)$ & \multirow{3}{*}{ NA } \\
\hline Previous AIDS diagnosis & $54(89)$ & \\
\hline Dual HIV-cancer diagnosis & $6(10)$ & \\
\hline \multicolumn{3}{|l|}{ ECOG functional status: } \\
\hline Fully active & $10(11)$ & \multirow{5}{*}{ NA } \\
\hline Restricted & $24(27)$ & \\
\hline Ambulatory & $17(19)$ & \\
\hline Limited self care & $25(28)$ & \\
\hline Completely disabled & $14(16)$ & \\
\hline \multicolumn{3}{|l|}{ Primary place of palliative care: } \\
\hline Home & $56(62)$ & \multirow{4}{*}{ NA } \\
\hline Inpatient unit & $27(30)$ & \\
\hline Outpatient clinic & $3(3)$ & \\
\hline Day care & $4(4)$ & \\
\hline \multicolumn{3}{|l|}{ Weeks under palliative care } \\
\hline Mean (SD) & $51.4(85.2) \dagger$ & \multirow{2}{*}{ NA } \\
\hline Median (range) & $15.0(0-427)$ & \\
\hline $\begin{array}{l}\text { ECOG=Eastern Cooperative Oncolog, } \\
{ }^{*} \text { Three missing. } \\
\text { †One missing. }\end{array}$ & applicable. & \\
\hline
\end{tabular}

Table 2 shows demographic data for patients and carers recruited across the participating sites. Across the sample, 27 participants were from an urban location, 36 in a peri-urban location, and 65 in a rural location. This reflects both the diverse areas served by the facilities (table 1) and the fact that many patients were either inpatients or living away from home. Table 3 gives a detailed breakdown of participants' characteristics by site.

\section{Qualitative findings}

We coded qualitative interview data under 10 main themes: disease history, physical symptoms and treatment, psychology, spirituality and religion, death and dying, socioeconomic problems, family, friends and community, healthcare services, and communication and information. Communication and information represented a central theme, referred to by 85 out of 90 patients in 143 passages of text ( 31 out of 38 carers referred to the theme in 35 passages). We broke down the wealth of data under this theme into the following sub-themes: sources of information, information needs, impact of unmet information needs, communication with general healthcare staff, and barriers to effective provision of information. We present the findings under these headings.

We have used some numerical counting in reporting findings, to help to describe the prevalence of particular experiences and views within the sample inter viewed. ${ }^{3839}$ As this is a qualitative study using purposive sampling, the use of numbers should not be taken to imply statistical representation of the population under consideration. Instead, we aim to represent the range and diversity of experiences and views. In rigorous qualitative research it is this range and diversity that can be inferred to the parent population, rather than the proportions found within the sample.

All the data reported have been anonymised. Identification codes quoted represent the site (A-E) and numerical code for the participant; carers' codes have the suffix "C". We specify the site when we report a finding particular to that site or make comparisons between sites.

\section{Sources of information}

Patients and caregivers reported a wide range of sources of information about the disease and its management. Healthcare providers (hospital, antiretroviral therapy clinic, family planning clinic, and palliative care team) were a key source of information, reported by 30 patients and 12 carers. Non-governmental organisations such as support groups also played an important role for some patients, and the media was also mentioned as a source of information, particularly by carers. Both patients and carers also talked about receiving information and support from friends, neighbours, and family members. At site E, patients reported receiving information and support from peers with the same condition, as well as from their church minister.

Such resourcefulness in accessing information was often necessitated by a lack of sufficient information 
Table 3 |Breakdown of characteristics of sample by site. Values are numbers (percentages) unless stated otherwise

\begin{tabular}{|c|c|c|c|c|c|c|c|c|c|c|}
\hline \multirow[b]{2}{*}{$\begin{array}{l}\text { Demographic } \\
\text { characteristic }\end{array}$} & \multicolumn{2}{|c|}{ Site A } & \multicolumn{2}{|c|}{ Site B } & \multicolumn{2}{|c|}{ Site C } & \multicolumn{2}{|c|}{ Site D } & \multicolumn{2}{|c|}{ Site $\mathrm{E}$} \\
\hline & $\begin{array}{l}\text { Patients } \\
(\mathrm{n}=20)\end{array}$ & Carers $(n=10)$ & $\begin{array}{l}\text { Patients } \\
(\mathrm{n}=20)\end{array}$ & Carers $(n=3)$ & $\begin{array}{l}\text { Patients } \\
(n=12)\end{array}$ & Carers $(n=3)$ & $\begin{array}{l}\text { Patients } \\
(\mathrm{n}=18)\end{array}$ & Carers $(n=12)$ & $\begin{array}{l}\text { Patients } \\
(\mathrm{n}=20)\end{array}$ & Carers $(n=10)$ \\
\hline $\begin{array}{l}\text { Mean (SD; range) age } \\
\text { (years) }\end{array}$ & $\begin{array}{l}43.1(12.5 ; \\
21-70)\end{array}$ & $\begin{array}{l}41.8(18.6 ; \\
19-77)\end{array}$ & $\begin{array}{l}46.3(17.4 \\
19-75)\end{array}$ & $\begin{array}{l}45.3(23.3 ; \\
29-72)\end{array}$ & $\begin{array}{c}35.0(7.6 ; 21- \\
49)\end{array}$ & $\begin{array}{l}40.3(15.0 \\
26-56)\end{array}$ & $\begin{array}{c}35.4(9.9 ; 20- \\
57)\end{array}$ & $\begin{array}{c}33.6(8.2 ; 25- \\
46)^{\star}\end{array}$ & $\begin{array}{l}52.0(18.4 \\
18-84)\end{array}$ & $\begin{array}{c}59.2(14.5 ; 35- \\
74)\end{array}$ \\
\hline Female & $15(75)$ & $8(80)$ & $11(55)$ & $3(100)$ & $10(83)$ & $2(67)$ & $10(56)$ & $9(75)^{*}$ & $12(60)$ & $10(100)$ \\
\hline \multicolumn{11}{|l|}{$\begin{array}{l}\text { Responsible for } \\
\text { children? }\end{array}$} \\
\hline Yes & $18(90)$ & $9(90)$ & $18(90)$ & $3(100)$ & $9(75)$ & $2(67)$ & $15(83)$ & $9(75.0)^{*}$ & $8(40)$ & $7(70)$ \\
\hline $\begin{array}{l}\text { Mean (SD; range) } \\
\text { No of children }\end{array}$ & $3.6(2.0 ; 1-9)$ & $3.7(2.2 ; 1-8)$ & $2.7(1.8 ; 1-7)$ & $1.3(0.6 ; 1-2)$ & $1.7(2.0 ; 1-2)$ & $2(0 ; 2)$ & $2.5(1.8 ; 1-8)$ & $3.1(0.8 ; 2-4)^{\star}$ & $3.3(1.5 ; 1-6)$ & $3.3(1.6 ; 1-6)$ \\
\hline $\begin{array}{l}\text { Mean (SD; range) } \\
\text { household size }\end{array}$ & $6.9(4.1 ; 2-20)$ & $8.7(5.3 ; 2-20)$ & $\begin{array}{c}4.32(4.0 ; 1- \\
10) \dagger\end{array}$ & $6(2.6 ; 4-9)$ & $4.8(1.7 ; 2-8)$ & $6(2.0 ; 4-8)$ & $\begin{array}{c}6.3(2.20 ; 4- \\
13)\end{array}$ & $\underset{\star}{7.9(7.0 ; 6-14)}$ & $3.7(2.2 ; 1-9)$ & $5.3(2.0 ; 2-9)$ \\
\hline \multicolumn{11}{|l|}{ Location of home: } \\
\hline Urban & 0 & 0 & 0 & 0 & $12(100)$ & $3(100)$ & 0 & 0 & $11(55)$ & $1(10)$ \\
\hline Peri-urban & $11(55)$ & $7(70)$ & $14(70)$ & $2(67)$ & 0 & 0 & 0 & 0 & $1(5)$ & $1(10)$ \\
\hline Rural & $9(45)$ & $3(30)$ & $6(30)$ & $1(33)$ & 0 & 0 & $18(100)$ & $12(100)$ & $8(40)$ & $8(80)$ \\
\hline \multicolumn{11}{|l|}{ Primary diagnosis: } \\
\hline MND & 0 & \multirow{3}{*}{ NA } & $1(5)$ & \multirow{3}{*}{ NA } & 0 & \multirow{3}{*}{ NA } & 0 & \multirow{3}{*}{ NA } & 0 & \multirow{3}{*}{ NA } \\
\hline Cancer only & $6(30)$ & & $8(40)$ & & $2(17)$ & & 0 & & $12(60)$ & \\
\hline HIV & $14(70)$ & & $11(55)$ & & $10(83)$ & & $18(100)$ & & $8(40)$ & \\
\hline \multicolumn{11}{|l|}{$\begin{array}{l}\text { Of HIV positive } \\
\text { patients: }\end{array}$} \\
\hline $\begin{array}{l}\text { On antiretroviral } \\
\text { therapy }\end{array}$ & $8(57)$ & \multirow{3}{*}{ NA } & $8(73)$ & \multirow{3}{*}{ NA } & $7(70)$ & \multirow{3}{*}{ NA } & $15(83)$ & \multirow{3}{*}{ NA } & $1(13)$ & \multirow{3}{*}{ NA } \\
\hline $\begin{array}{l}\text { Previous AIDS } \\
\text { diagnosis }\end{array}$ & $11(79)$ & & $11(100)$ & & $10(100)$ & & $17(94)$ & & $5(63)$ & \\
\hline $\begin{array}{l}\text { Dual HIV-cancer } \\
\text { diagnosis }\end{array}$ & $3(21)$ & & 0 & & $1(10)$ & & $1(6)$ & & $1(13)$ & \\
\hline \multicolumn{11}{|l|}{$\begin{array}{l}\text { ECOG functional } \\
\text { status: }\end{array}$} \\
\hline Fully active & $1(5)$ & \multirow{5}{*}{ NA } & 0 & \multirow{5}{*}{ NA } & $1(8)$ & \multirow{5}{*}{ NA } & $2(11)$ & \multirow{5}{*}{ NA } & $6(30)$ & \multirow{5}{*}{ NA } \\
\hline Restricted & $10(50)$ & & 0 & & $4(33)$ & & 0 & & $10(50)$ & \\
\hline Ambulatory & 0 & & $12(60)$ & & $3(25)$ & & 0 & & $2(10)$ & \\
\hline Limited self care & $5(25)$ & & $6(30)$ & & $2(17)$ & & $12(67)$ & & 0 & \\
\hline $\begin{array}{l}\text { Completely } \\
\text { disabled }\end{array}$ & $4(20)$ & & $2(10)$ & & $2(17)$ & & $4(22)$ & & $2(10)$ & \\
\hline \multicolumn{11}{|l|}{$\begin{array}{l}\text { Primary place of } \\
\text { palliative care: }\end{array}$} \\
\hline Home & $16(80)$ & & $5(25)$ & & $12(100)$ & & $7(39)$ & & $16(80)$ & \\
\hline Inpatient unit & $1(5)$ & & $14(70)$ & & 0 & & $11(61)$ & & $1(5)$ & \\
\hline Outpatient clinic & $3(15)$ & NA & 0 & NA & 0 & NA & 0 & NA & 0 & NA \\
\hline Day care & 0 & & $1(5)$ & & 0 & & 0 & & $3(15)$ & \\
\hline $\begin{array}{l}\text { Weeks under } \\
\text { palliative care: }\end{array}$ & & & & & & & & & & \\
\hline Mean (SD) & $60.7(69.8) \dagger$ & & $19.3(35.4)$ & & $47.0(43.3)$ & 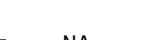 & $4.0(7.3)$ & & $120.2(135.4)$ & No \\
\hline Median (range) & $29.0(3-264) \dagger$ & NA & $2.0(1-140)$ & NA & $29.0(3-104)$ & NA & $0.50(0-28)$ & NA & $46.5(3-427)$ & NA \\
\hline
\end{tabular}

from their healthcare services. For example, an AIDS patient stated, "No, they [general healthcare staff] never explained what HIV was all about. The little information I had is what I gathered from my community and the media" (B037). Similarly, a cancer patient reported, "Sometimes you get a decent guy [hospital clinician], but then he's so stressed out that he hasn't got time to talk to you. Our knowledge of cancer was zero and we got most of our information through our daughter helping us out and through the internet"
(E017). The patient's wife, his primary caregiver, reiterated in her interview, "There was very little, we had to learn so much ourselves, we've had to read up on it. My daughter got printouts off the internet, the computer, and also from books" (E017C).

Participants clearly recognised that healthcare staff needed to provide more information. This is illustrated by a cancer patient who said, "Yes, I definitely think they [general healthcare staff] should give out more, especially to someone who's just been diagnosed, for 
them to know exactly what they're going through, to be able to speak to the doctors and ... ask what's wrong and what stage it was at" (E007). However, one patient stated that she wanted to know as little as possible:

Interviewer: "Is there anything else you would like more information about?"

Respondent: "Uh, uh! The less I know the better!" (E012, cancer patient).

Where palliative care services had actively provided information and support, respondents expressed gratitude. For example, the mother of an AIDS patient said, "The information that you gave us, and the help you gave us, made my son get well. Oh, I love you, my children. If I see you coming up there on the road I just feel so happy" (E016C).

\section{Information needs}

Patients and caregivers were asked if they would like additional information on any subjects. Nineteen patients and two carers reported that they did not need any additional information; however, 12 of these patients ( 10 from site $\mathrm{D}$ and two from site $\mathrm{B}$ ) were not probed further for any unanswered questions (see "Barriers to effective information provision" for the significance of this). Box 2 summarises patients' needs for information. At site A, seven patients also wanted to know whether their disease could be cured, suggesting lack of insight.

Across the sites, the topic on which caregivers most often reported needing more information was the

\section{Box 2 Information needs of patients: important topics}

\section{Causes and symptoms ( $\mathrm{n}=29)$}

"I wanted to know that for me to get this disease and suffer from it ... what wasn't right inside my body?" (C065, cancer patient)

"What I know is not enough ... I would like to know all about cancer and its limitations" (A023, cancer patient)

"They have not explained why my legs are so weak and painful, but in hospital they told me I am HIV positive ... I don't think [the information] is enough, I still need to know what is wrong with my legs" (B012, AIDS patient)

"I do have other things I would like to know, like getting a baby when you are HIV positive" (B035, AIDS patient)

\section{Progression, treatment, and management of disease $(n=22)$}

"I would want to know maybe the first stage we are going to give this [and] then we shall review A, B, C, D ... I need to know how many stages I am going to go through ... That information should be there" (A027, cancer patient)

"I would like to know for how long will I be taking these antiretrovirals, whether it will be for the rest of my life" (D070, AIDS patient)

"I would like to know more about it-what can I do so that I can become better? What can I use to make my life easier?" (E041, AIDS patient)

Financial and social support $(n=9)$

"I also would like to know if the help got from [X] hospice will continue or after some time it will be stopped. Because I would need assistance like food, finance, building a house to help my children in future" (A024, patient with AIDS and cancer)

Supporting others $(\mathrm{n}=2)$

"Yes, there is something I would like to know: as I am HIV positive, how can I help the others that are HIV positive too?" (E068, AIDS patient) patient's disease and its progression. For example, the caregiver of a patient with cancer and AIDS stated, "They say about the CD4 count that when they decrease her life is in trouble. So I need to know her position now. Because they said the medication she is taking is for tuberculosis, yet for me I thought she started straight forward taking the antiretrovirals" (A030C). Other information needs of caregivers concerned symptoms and their management and financial and social support.

Nine patients and three caregivers reported not knowing which questions to ask staff or said that they were unable to judge if they had been given enough information. A patient with motor neurone disease exemplifies this: "They told me about my illness, though I don't know whether it was enough, as I am not familiar with the disease" (B014). This highlights patients' and caregivers' reliance on healthcare staff to start and guide conversations and to share information, although staff members do not always fulfil this expectation (see "Communication with general healthcare staff').

\section{Impact of unmet information needs}

Although participants were not asked specifically how their need for more information affected their lives, several interviews showed that being uninformed contributed to patients' and carers' worry. Patients described the impact on their ability to plan for the future, for example: "Knowing medication is important . . . because it is costly to get medicine, so you need to plan for it way ahead" (A027, cancer patient) Carers also expressed concerns caused by their lack of information-for example, a carer of a patient with AIDS and tuberculosis stated, "Even me, I'm coughing and coughing, I don't know what's going on and I'm getting worried" (E069C).

A lack of information seemed to reduce patients' ability to care for themselves, whereas being fully informed helped them to manage their conditions better, as reported by an HIV positive patient: "Yes, I was told everything at the clinic about HIV and AIDS, and I think I have used that to my advantage, because here I am now, still alive and getting stronger" (B036). Similarly, unmet needs for information affected the quality of care that some family members were able to provide, as exemplified by the carer of a patient with AIDS: "It is not enough information, because there are things that you would like to ask or to know and I'm not sure where to get the information. The clinics are very busy and don't have the time for the questions. I wish I could get the information, because one day she is going to be very sick and I won't know how to look after her" (E068C).

Conversely, being well informed seemed to have a beneficial impact on some patients' ability to cope. A patient with colon cancer, for example, described how being informed contributed to a sense of inner peace.

Interviewer: "Have you been able to find peace during your illness?"

Respondent: "Yes I did have peace." 
Table 4 |Barriers to information provision and recommended solutions

Barriers identified

Symptom related: confusion; memory loss

Cultural context related: patients and caregivers not empowered to ask questions; social desirability factors; differences in first language and socioeconomic/cultural background of patients/caregivers and staff

Staff related: paternalism; lack of time; family members excluded from discussions

\section{I: "How?" \\ R: "When they have explained about everything"} (C065).

Another patient reported how access to information and open communication had helped her family to deal with the condition: "We discuss it, we talk about it. We are reading books about it. It has helped us" (E003, patient with ovarian and breast cancer).

\section{Communication with general healthcare staff}

Respondents reported both positive and negative experiences of communication with general healthcare staff encountered in hospitals and clinics. Poor communication with generalist staff was a central theme across the sites, as illustrated by a cancer patient at site A: "When I went to [X hospital], the problem we have is lack of information ... you need to go through a proper process of information about what the disease is, the likely treatment, the side effects of that treatment, because there are several of them . . . I mean, [you need] that emotional support" (A027). This view was shared by a patient with prostate cancer at site E, who stated, "The information level is shocking, they [hospital staff] don't even want to give you PSA [prostate specific antigen] results, you know, we're not kids! And they think I don't know what they think - that you're going to die of fright if they tell you" (E017).

Four patients described the trauma of having bad news broken to them insensitively; for example, "I asked them if I was going to die. They told me that I won't die if I take my treatment I will be given. I was shocked and shattered by the news. I cried a lot and pleaded with the doctor to kill me, because I felt I was already dead. I was referred to hospital and I continued with my plea, but a fellow patient who talked me out of that thought helped me" (B011, AIDS patient).

Across the sites, four patients and a caregiver described being misinformed by healthcare staff or test results not being shared with them. Two AIDS patients at site B illustrate this.

Interviewer: "When you started being sick did nobody ever suggest an HIV test?"

Respondent: "No, they never did the test."

I: "How did you know that you had shingles?"

R: "The doctors told me, and they said that was caused by heat and never told me they can also be caused by HIV" (B035).
Recommended solutions

Tailor communication to needs and abilities of individual patients and caregivers; check patient's understanding after key discussions

Continuous assessment of information needs throughout disease trajectory; culturally sensitive, proactive provision of information

Education and training for generalists in palliative care communication skills, including breaking bad news and family conferences; record key discussions in patient notes; access to counsellors for referral of patient where necessary; advice and support from palliative care trained staff throughout disease trajectory

Interviewer: "Did they ever tell you what you are suffering from?"

Respondent: "No, blood samples were taken for various tests, but I never got the result" (B012).

At site E, four patients described feeling mistreated, objectified, or spoken to without respect while in hospital - for example: "Only the matron was rude. When I was very sick in X [hospital] . . I want[ed] water so I pressed the bell. 'Wake up and take the water,' [the matron said]. I said, 'I can't wake up.' I tried to wake up but I fell. Then my husband and my sister-in-law, they saw me, then my brother's wife she went into the office and said, 'How come when they ring the bell, they want water, you can't look after the patient? She's on the floor"' (E005, breast cancer patient).

Caregivers across sites discussed feelings of being shut out by "secretive" staff. Three caregivers reported not being told the patient's diagnosis directly, but learning it from the medical notes or from being sent on a course. For example, one caregiver said, "Up until now I don't know what's wrong with her, I'm just presuming . . . because at [the HIV clinic] they educated me on HIV and caring for someone who is positive" (E064C).

However, positive experiences of communication with healthcare staff were also reported. A cancer patient described how her doctor helped her to break the diagnosis to her children, and two other patients reported a close relationship with staff. For example, a patient at site E, who was an ex-nurse, said, "Both my oncologists are fantastic. I see both of them, I started with $\operatorname{Dr}[\mathrm{X}]$, and then she has a partner who I see when she's away ... They both know exactly what's going on. You can ask them anything you like and the sisters there are all oncology trained, fantastic" (E004). The same patient described how open communication about prognosis, future care, and treatment options had helped her to come to terms with her condition: "Dr [X], the oncologist at [X hospital], told me all the dos and don'ts and said I could think about it ... The doctor explained a lot, that every day there was something new and they could try all sorts of different things. She said that if I ran out of money she could arrange for me to be seen at the government hospital" (E004).

Similarly, the carer of a patient with HIV described the positive impact of receiving information from a clinician: "He [the patient] used to have his own 
plate, mug and a spoon until I went into [X] hospital and spoke with a doctor there. The doctor took me into a small room; it was me and the doctor only. He told me about [the patient's] illness and he educated me that we can use the same plate. What I must watch out for is razor blades, enemas, and I must protect my hands if I'm doing the washing or bathing so that I don't catch the virus. When I came back I called the whole family. I told them what the doctor had said to me. Now there is no problem. We use the same dishes, we share everything" (E041C).

\section{Barriers to effective information provision}

Across four of the sites (A, B, C, E), eight patients and five caregivers stated that they had had enough information about their condition but on further probing revealed unanswered questions and unmet needs for information. A 50 year old woman with cancer and AIDS illustrates this tendency.

Interviewer: "Has this information you have got from your doctor, and maybe other people, been enough for you?"

Respondent: "I feel I have got enough information about my illness."

I: "What would you like more information about?"

R: "I need more information about what cancer actually is, if it can be cured, and how soon. I would also like information on any social or financial support I could get either around [the hospice] or from organisations" (A024).

This tendency seems to indicate low expectations of health care, which might also be cultural.

Three patients reported confusion or memory loss that made comprehending and retaining information difficult. This may have been as a reaction to receiving bad news or difficult medical information, a manifestation of the disease's symptoms, or a side effect of treatment. For example: "Everything happened so fast that I can't remember everything that I was told ... I don't remember the information they gave me then, so I don't know if it's been enough" (E062, AIDS patient).

Staff related barriers were also described. A patient and a caregiver from site $\mathrm{E}$ reported that general healthcare staff were often too busy or stressed to communicate well: "The clinics are very busy and don't have the time for the questions. I wish I could get the information because one day she is going to be very sick and I won't know how to look after her" (E068C, caregiver of AIDS patient). Three patients found the language used by staff difficult to understand and criticised healthcare staff for adopting a paternalistic approach to provision of information; for example: "They use words that you don't understand and we have to ask, and there are times when they discuss you and your condition with other doctors or other medical doctors, you know, the student ones, while you are there. They discuss the whole thing about you while you just sit there, dumb, looking at them" (E003, cancer patient). Table 4 summarises the barriers to effective provision of information.

\section{DISCUSSION}

This is the first study in Africa to try to understand experiences of communication and information giving among patients with incurable progressive disease and their informal caregivers and to identify their unmet needs. Most patients and caregivers lacked information and had unanswered questions about their conditions. This situation seemed to exist in spite of them drawing on a wide range of sources for information. Patients and caregivers often considered general medical services to be inadequate at providing accessible information that met their needs. Although patients and caregivers appreciated efforts made by their palliative care team to provide information, many still had unanswered questions.

Poor knowledge and provision of information adversely affected patients' and caregivers' ability to cope with their situation, directly affecting caregivers' ability to care for patients, as well as patients' ability to care for themselves and plan for the future. For both groups, not having the information they needed was related to anxiety about the disease and the future.

\section{Limitations of study}

The use of different interviewers at the five participating sites means that data were collected by researchers with varying degrees of experience and with differing backgrounds and interviewing skills, although they all received the same training and support. This resulted in some variability in the depth of the interviews; those from sites A, B, and E were more detailed and probing than those from sites $\mathrm{C}$ and $\mathrm{D}$. Variation in quality of data is perhaps an inevitable result of working in resource strained settings where clinical staff trained in research are lacking; the researchers used in this study were the first local palliative care research nurses employed in Africa. However, despite variation in data quality, as our findings show, the interviews as a set are rich enough to provide detailed data on patients' and carers' information needs and experiences of communication across the sites. To fully understand patients' and carers' experiences and needs at sites C and D, more in-depth interviewing would be needed.

Owing to resource constraints, translation of the transcripts was done only once, with no back translation. However, translations were peer reviewed by service staff and translation of complex terms or phrases was debated until consensus was reached. We aimed in this way to minimise the loss of "rich" language (for example, idiomatic meanings).

The lead data analyst (LS) is European and has not lived in Africa, which could potentially lead to aspects of the data being misunderstood. As described, we minimised this by regular consultation with the local African project team members throughout data collection, analysis, and dissemination.

Data were collected in a complex context of diverse cultures and languages. Differences in the socioeconomic, ethnic, and cultural backgrounds of interviewers and interviewees were inevitable and may have affected the responses given. However, 


\section{WHAT IS ALREADY KNOWN ON THIS TOPIC}

Research from developed countries shows that lack of information on causes, symptoms, treatment, and progression of diseases is associated with poor outcomes in patients and caregivers

Little research has been done on the information needs of patients with incurable progressive disease and their families in sub-Saharan Africa or on their experiences of communication with healthcare staff

Evidence is therefore lacking on how best to meet the information needs of these patients and their families at a service level

\section{WHAT THIS STUDY ADDS}

Patients and caregivers receiving palliative care in South Africa and Uganda are often uninformed about the patient's disease and its management, which impairs their ability to cope with the condition and plan for the future

Key areas of information need are causes and symptoms; progression, treatment, and management of disease; and financial and social support

"matching" interviewer and interviewee is not always practical or even possible in settings with multiple tribes and languages and does not necessarily deliver better results. ${ }^{4041}$

Finally, within the sub-Saharan African population, the participants in this study are a relatively unusual group in that all were receiving palliative care. Most people dying with advanced illness in South Africa and Uganda, and indeed in the rest of sub-Saharan Africa, may have even less access to information and care than this sample.

\section{Implications for clinicians and policy makers}

This is the first study to show that unmet needs for information about symptoms and their management, and about the causes, progression, and treatment of disease, are common among patients receiving palliative care and their caregivers in sub-Saharan Africa. As in other, non-African studies, participants were found to rely on healthcare providers as a major source of information on the management of their symptoms, ${ }^{4243}$ but this information was not always forthcoming.

Our findings have direct relevance for service provision and development in sub-Saharan Africa, summarised in table 4 . On the basis of the barriers identified in the data, we make the following recommendations.

\section{Education, training, and support}

All clinical staff should receive generalist training in palliative care skills, including communication and basic counselling. In this study, experiences of poor communication and a lack of counselling were considerable and detrimental. Patients and caregivers experience high levels of worry and fear, so access to staff with counselling skills is imperative throughout the disease trajectory. ${ }^{44}$ Joint working or liaison with professionals trained in palliative care is also recommended to ensure that general healthcare staff receive the support they need in complex cases.

\section{Information provision}

Tailored to the individual-Our findings show that specific needs for information vary between individual people, who may rely on healthcare professionals for information on a range of topics depending on their changing needs and preferences. Communication should therefore be individually tailored according to needs, preferences, and abilities, assessed repeatedly at key points in the disease trajectory. ${ }^{20}$ Information should be expressed in lay terms and take into account the psychological impact of receiving difficult news, as well as symptoms such as memory loss, also reported in other studies. ${ }^{45}$ Evidence from other studies suggests that tailored information is recalled better than more general information, ${ }^{46}$ and question prompt sheets and audio recordings of consultations also improve recall. ${ }^{47}$ However, in communities with high levels of illiteracy, pictorial educational materials and face to face teaching may be more economical and effective. $^{48}$

Reflexive and proactive-Participants in this study showed a tendency to say that they had all the information they needed but on further probing reveal important unanswered questions. Low expectations and social desirability seem to play a role here; some service users feel that they should seem grateful for the care they receive, even when their needs are not being met. For this reason, staff members need to be aware of, and take into consideration, how differences in cultural norms and perceptions of social power may affect their relationships with patients and caregivers. ${ }^{49}$ To avoid needs for information going undetected, we recommend that healthcare staff should question patients and caregivers proactively about their information needs and check their understanding. ${ }^{50}$

Open and honest - Communication with patients and caregivers should be open and honest, in line with our findings on patients' and carers' preferences and the negative impact of unmet information needs. A recent international systematic review found that hiding or distorting the truth does not engender hope but may instead increase patients' fear, although no studies from developing country settings were identified. ${ }^{51}$ As in our study, the minority of patients may prefer non-disclosure and find hope in avoiding the facts. In this case their autonomy should be respected, but their preferences should be assessed and re-negotiated throughout the disease trajectory.

Documented-Barriers to good communication with patients and carers identified from our findings include time pressures on staff and working in an understaffed environment. To ensure effective multidisciplinary care in resource stretched conditions, records should be kept of discussions between healthcare staff and patients about diagnosis, prognosis, treatment, and end of life decisions, and all relevant staff should have access to these. ${ }^{52}$

For both patient and caregiver-Many carers in this study had unanswered questions about the patient's disease and related subjects and were negatively affected by unmet needs for information. The data 
show that some carers are excluded from discussions with healthcare staff about the patient's disease and treatment and that carers play a key role as information providers to the rest of the family and larger community. Services must therefore work closely with families and volunteer caregivers in the community, empowering them to provide the care the patient needs, including sensitive and accurate communication. ${ }^{53}$ Family conferences may help to ensure that family members' information needs are met and that family members provide reliable information to others.

\section{Future research}

Communication and provision of information is one of many elements in the care of patients with incurable progressive disease and their families that needs further research in Africa. To expand, clarify, and potentially confirm our findings, research is required to explore patients' and caregivers' communication needs in more depth and in a wider variety of settings. Research is required into the needs of general healthcare staff and specialist palliative care staff for training and support to inform the development of health services in sub-Saharan Africa. Given the diversity of spoken languages and high levels of health illiteracy in the region, novel, non-written methods of providing information need to be developed and validated for these settings. ${ }^{54}$ Quantitative studies are also required to identify variables that predict specific information needs. A recent international systematic review found no research papers on this topic from Africa. ${ }^{20}$

In developed countries, a strong focus on fostering best practice in communication and provision of information has existed, in order to meet the needs of patients and caregivers and increase quality of care. In countries with limited resources, which often bear a greater disease burden, good quality palliative care is urgently needed, and the same focus is also essential.

We are very grateful to all the patients and caregivers who participated, the service staff who helped with recruitment, and the Big Lottery Fund UK and Cicely Saunders International for funding this study. We thank Claire Gillespie and Penny Gwacela at South Coast Hospice, Patricia Ndlovu at Philanjalo Hospice, and Kabuye Deo and Lillian Mpeirwe at Hospice Africa Uganda for assisting with interviews, and Fliss Murtagh and Jonathan Koffman for comments on a previous draft

Contributors: $\mathrm{RH}$ and IJH applied for funding. $\mathrm{RH}$, IJH, and LS designed the study. LS and RH trained the nurses and oversaw data collection, transcription, and analysis. GA, TM, and KM recruited participants and conducted, transcribed, and translated interviews. ND, LG, APM, LS, and BP supervised recruitment, data collection, transcription, and translation. LS analysed the data and wrote the first draft of the paper, supervised by $\mathrm{RH}$ and $\mathrm{IJH}$. All authors commented on and contributed to the final draft. $\mathrm{RH}$ is the guarantor.

Funding: This study was sponsored by a grant from the Big Lottery UK through Cicely Saunders International. The authors declare their independence from the funders.

Competing interests: None declared.

Ethical approval: The study was reviewed and approved by the ethics review boards of the Universities of Cape Town, KwaZulu Natal, and Witwatersrand; the Ugandan National Council for Science and Technology; Hospice Africa Uganda; and the Hospice Palliative Care Association of South Africa.

1 UNAIDS. AIDS epidemic update 2007. Geneva: WHO, 2007.
2 UNAIDS, WHO. UNAIDS/WHO 2006 report on the global AIDS epidemic. Geneva: WHO, 2006.

3 Harding R, Molloy T, Easterbrook P, Frame K, Higginson IJ. Is antiretroviral therapy associated with symptom prevalence and burden? Int J STD AIDS 2006;17:400-5.

4 Selwyn PA, Forstein M. Overcoming the false dichotomy of curative vs palliative care for late-stage HIV/AIDS: "let me live the way I want to live, until I can't". JAMA 2003;290:806-14.

5 Collins K, Harding R. Improving HIV management in sub-Saharan Africa: how much palliative care is needed? AIDS Care 2007;19:1304-6.

6 Harding R, Higginson IJ. Palliative care in sub-Saharan Africa. Lance 2005;365:1971-7.

7 Harding R, Karus D, Easterbrook P, Raveis VH, Higginson IJ, Marconi K. Does palliative care improve outcomes for patients with HIV/AIDS? A systematic review of the evidence. Sex Transm Infect 2005;81:5-14.

8 Parkin P, Sitas F, Chirenje M, Stein L, Abratt R, Wabinga H. Part I: cancer in indigenous Africans-burden, distribution, and trends. Lancet Oncology 2008;9:683-92.

9 Clark D, Wright M, Hunt J, Lynch T. Hospice and palliative care development in Africa: a multi-method review of services and experiences. J Pain Symptom Manage 2007;33:698-710.

10 Foster S. Supply and use of essential drugs in sub-Saharan Africa: some issues and possible solutions. Soc Sci Med 1991;32:1201-18.

11 Soares L. Poor social conditions, criminality and urban violence: unmentioned barriers for effective cancer pain control at the end of life. J Pain Symptom Manage 2003;26:693-5.

12 Swartz L, Dick J. Managing chronic disease in less developed countries. BM/ 2002:325:914-5.

13 Harding R, Stewart K, Marconi K, O'Neill JF, Higginson IJ. Current HIV/ AIDS end-of-life care in sub-Saharan Africa: a survey of models, services, challenges and priorities. BMC Public Health 2003;3:33.

14 Ministry of Health RoU. National sector strategic plan 2000/01 2004/05. Kampala: Ministry of Health, 2000.

15 Jagwe J, Merriman A. Uganda: delivering analgesia in rural Africa: opioid availability and nurse prescribing. J Pain Symptom Manage 2007;33:547-51.

16 Logie DE, Harding R. An evaluation of a morphine public health programme for cancer and AIDS pain relief in Sub-Saharan Africa. BMC Public Health 2005;5:82.

17 Gwyther E. South Africa: The status of palliative care. J Pain Symptom Manage 2002;24:236-8.

18 Beck SL. Health policy, health services, and cancer pain management in the new South Africa. J Pain Symtomp Manage 1999;17:16-26.

19 Kutner JS, Steiner JF, Corbett KK, Jahnigen DW, Barton PL. Information needs in terminal illness. Soc Sci Med 1999;48:1341-52.

20 Parker SM, Clayton JM, Hancock K, Walder S, Butow PN, Carrick S, et al. A systematic review of prognostic/end-of-life communication with adults in the advanced stages of a life-limiting illness: patient/ caregiver preferences for the content, style, and timing of information. J Pain Symptom Manage 2007;34:81-93.

21 Thorne SE, Bultz BD, Baile WF. Is there a cost to poor communication in cancer care? A critical review of the literature. Psychooncology 2005;14:875-84.

22 Mager WM, Andrykowski MA. Communication in the cancer 'bad news' consultation: patient perceptions and psychological adjustment. Psychooncology 2002;11:35-46.

23 Harding R, Powell RA, Downing J, Connor SR, Mwangi-Powell F, Defilippi K, et al. Generating an African palliative care evidence base: the context, need, challenges and strategies. J Pain Symptom Manage 2008;36:304-9.

24 Sepulveda C, Habiyambere V, Amandua J, Borok M, Kikule E, Mudanga B, et al. Quality care at the end of life in Africa. BM 2003;327:209-13.

25 Sukati NA, Mndebele SC, Makoa ET, Ramukumba TS, Makoae LN, Seboni NM, et al. HIV/AIDS symptom management in Southern Africa. J Pain Symptom Manage 2005;29:185-92.

26 Murray SA, Grant E, Grant A, Kendall M. Dying from cancer in developed and developing countries: lessons from two qualitative interview studies of patients and their carers. BMJ 2003;326:368.

27 Grant E, Murray SA, Brown I. A good death in rural Kenya? Listening to Meru patients and their families talk about care needs at the end of life. J Palliat Care 2003;19:159-67.

28 Kikule E. A good death in Uganda: survey of needs for palliative care for terminally ill people in urban areas. BMI 2003;327:192-4.

29 Greenhalgh T, Taylor R. How to read a paper: papers that go beyond numbers (qualitative research). BMJ 1997;315:740-3.

30 Selman L, Harding R, Beynon T, Hodson F, Coady E, Hazeldine C, et al. Improving end of life care for chronic heart failure patients-"Let's hope it'll get better, when I know in my heart of hearts it won't". Heart 2007;93:963-7.

31 Kuzel AJ. Sampling in qualitative inquiry. In: Crabtree BF, Miller WL, eds. Doing qualitative research. London: Sage, 1999:33-45. 
32 Creed-Kanashiro H, Ore B, Scurrah M, Gil A, Penny M. Conducting research in developing countries: experiences of the informed consent process from community studies in Peru. J Nutr 2005;135:925-8.

33 Shapiro HT, Meslin EM. Ethical issues in the design and conduct of clinical trials in developing countries. $N$ Engl J Med 2001;345:139-42.

34 Oken M, Creech R, Tormey D, Horton J, Davis T, McFadden E, et al. Toxicity and response criteria of the Eastern Cooperative Oncology Group. Am J Clin Oncol 1982;5:649-55.

35 Pope C, Ziebland S, Mays N. Analysing qualitative data. BMJ 2000;320:114-6.

36 Mays $\mathrm{N}$, Pope C. Assessing quality in qualitative research. BMJ 2000;320:50-2.

37 Armstrong D, Gosling A, Weinman J, Marteau T. The place of interrater reliability in qualitative research: an empirical study. Sociology 1997;31:597-606

38 Sandelowksi M. Real qualitative researchers do not count: the use of numbers in qualitative research. Res Nurs Health 2001;24:230-40.

39 Seale C. Using numbers: the quality of qualitative research. London: Sage, 1999:119-39.

40 Gunaratnam Y. Researching 'race' and ethnicity: methods, knowledge and power. London: Sage, 2003.

41 Graham J, Grewal I, Lewis J. Ethics in social research: the views of research participants. London: Government Social Research Unit, 2007.

42 Sukati NA, Mndebele SC, Makoa ET, Ramukumba TS, Makoae LN, Seboni NM, et al. HIV/AIDS symptom management in Southern Africa. J Pain Symptom Manage 2005;29:185-92.

43 Rutten LJF, Arora NK, Bakos AD, Aziz N, Rowland J. Information needs and sources of information among cancer patients: a systematic review of research (1980-2003). Patient Educ Couns 2005;57:250-61.

44 Makoae LN, Seboni NM, Molosiwa K, Moleko M, Human S, Sukati NA, et al. The symptom experience of people living with HIV/AIDS in southern Africa. J Assoc Nurses AIDS Care 2005;16(3):22-32.

45 Shawn ER, Campbell L, Mnguni MB, Defilippi KM, Williams AB. The spectrum of symptoms among rural South Africans with HIV infection. J Assoc Nurses AIDS Care 2005;16(6):12-23.
46 McPherson C, Higginson IJ, Hearn J. Effective methods of giving information in cancer: a systematic literature review of randomized controlled trials. J Public Health Med 2001;23:227-34.

47 Clayton JM, Butow PN, Tattersall MHN, Devine RJ, Simpson JM, Aggarwal G, et al. Randomized controlled trial of a prompt list to help advanced cancer patients and their caregivers to ask questions about prognosis and end-of-life care. J Clin Oncol 2007;25:715-23.

48 Petersen I, Mason A, Bhana A, Bell CC, McKay M. Mediating social representations using a cartoon narrative in the context of HIV/AIDS -the AmaQhawe family project in South Africa. J Health Psychol 2006;11:197-208.

49 Van Den Berg M, Nasaba R, Nieuwmeyer SM. Communicating with patients and their families. In: Gwyther L, Merriman A, Mpanga Sebuyira L, Schietinger $\mathrm{H}$, eds. A clinical guide to supportive and palliative care for HIV/AIDS in Sub-Saharan Africa. APCA, NHPCO, FHSSA,

2006:207-18 (available at www.fhssa.org/i4a/pages/Index.cfm? pagelD=3359).

50 Williams MV. Recognizing and overcoming inadequate health literacy, a barrier to care. Cleve Clin J Med 2002;69:415-8.

51 Clayton JM, Hancock K, Parker S, Butow PN, Walder S, Carrick S, et al. Sustaining hope when communicating with terminally ill patients and their families: a systematic review. Psychooncology 2007;17:641-59.

52 Curtis JR. Patient-clinician communication. In: O’Neill JF, Selwyn PA, Schietinger $\mathrm{H}$, eds. A clinical guide to supportive and palliative care for HIV/AIDS. USA: Health Resources and Services Administration, 2003.

53 Sepulveda C, Habiyambere V, Amandua J, Borok M, Kikule E, Mudanga B, et al. Quality care at the end of life in Africa. BM 2003;327:209-13.

54 Knapp P, Raynor DK, Jbar AH, Price SJ. Interpretation of medication pictograms by adults in the UK. Ann Pharmacother 2005;39:1227-33.

Accepted: 19 December 2008 